\title{
Computational Modeling of Retinotopic Map Development to Define Contributions of EphA-EphrinA Gradients, Axon-Axon Interactions, and Patterned Activity
}

\author{
Paul A. Yates, ${ }^{1, *}$ Alex D. Holub, ${ }^{2, \dagger}$ Todd McLaughlin, ${ }^{1}$ Terrence J. Sejnowski, ${ }^{2}$ \\ Dennis D.M. O'Leary' \\ ${ }^{1}$ Molecular Neurobiology Laboratory, The Salk Institute, 10010 North Torrey Pines Road, La Jolla, \\ California 92037 \\ ${ }^{2}$ Computational Neurobiology Laboratory, The Salk Institute, 10010 North Torrey Pines Road, La \\ Jolla, California 92037
}

Received 11 June 2003; accepted 11 August 2003

\begin{abstract}
The topographic projection of retinal ganglion cell (RGC) axons to mouse superior colliculus (SC) or chick optic tectum (OT) is formed in three phases: RGC axons overshoot their termination zone (TZ); they exhibit interstitial branching along the axon that is topographically biased for the correct location of their future $\mathrm{TZ}$; and branches arborize preferentially at the $\mathrm{TZ}$ and the initial exuberant projection refines through axon and branch elimination to generate a precise retinotopic map. We present a computational model of map development that demonstrates that the countergradients of EphAs and ephrinAs in retina and the OT/SC and bidirectional repellent signaling between RGC axons and OT/SC cells are sufficient to direct an initial topographic bias in RGC axon branching. Our model also suggests that a proposed repellent action of EphAs/ephrinAs present on RGC branches and arbors added to that of EphAs/ephrinAs expressed by OT/SC cells is required to progressively restrict branching and arborization to topographically correct locations and eliminate axon overshoot. Simulations show that this molecular framework alone can develop considerable topographic order and refinement, including axon elimination,
\end{abstract}

a feature not programmed into the model. Generating a refined map with a condensed $\mathrm{TZ}$ as in vivo requires an additional parameter that enhances branch formation along an RGC axon near sites that it has a higher branch density, and resembles an assumed role for patterned neural activity. The same computational model generates the phenotypes reported in ephrinA deficient mice and Is12EphA3 knockin mice. This modeling suggests that gradients of counter-repellents can establish a substantial degree of topographic order in the OT/SC, and that repellents present on RGC axon branches and arbors make a substantial contribution to map refinement. However, competitive interactions between RGC axons that enhance the probability of continued local branching are required to generate precise retinotopy. ๑ 2004 Wiley Periodicals, Inc. J Neurobiol 59: 95-113, 2004

Keywords: axon arborization; axon branching; axon competition; axon elimination; axon guidance; axon repellents; bidirectional signaling; ephrinA knockout mice; Isl2-EphA3 knockin mice; retinotectal projection; topographic mapping

\footnotetext{
* Present address: Massachusetts Eye and Ear Infirmary, 243 Charles St., Boston, MA 02114.

${ }^{\dagger}$ Present address: California Institute of Technology, 136-93, Pasadena, CA 91125.

Correspondence to: D.D.M. O'Leary (doleary@salk.edu). (D.O.).

Contract grant sponsor: NIH; contract grant number: EY07025
}

\footnotetext{
Contract grant sponsor: Neuroplasticity of Aging Training Grant; contract grant number: T32 AG00216 (T.M.).

(C) 2004 Wiley Periodicals, Inc.
}

DOI 10.1002/neu.10341 


\section{INTRODUCTION}

Sensory pathways in the nervous system are organized in an orderly manner, termed topographic maps, that re-represent the sensory periphery within target structures in the brain. The axonal projection of retinal ganglion cells (RGCs) to their midbrain target, the superior colliculus (SC) in mammals and the optic tectum (OT) in other vertebrates, has been the preeminent model for defining mechanisms that control the development of topographic maps, as well as for generating computational models of this process. Topographic map development has been thought to be dependent upon two distinct mechanisms: gradients of axon guidance molecules and patterned neural activity. Computational models have shown that, in principal, patterned neural activity can drive the development of topographic maps that initially have little order (Willshaw and von der Malsburg, 1976; Montague et al., 1991), but experimental manipulations show that a considerable degree of order can develop, and much of the subsequent refinement can occur in the absence of neural activity (Harris, 1980, 1984; Kobayashi et al., 1990; Stuermer et al., 1990; Simon et al., 1992; O’Rourke et al., 1994).

The chemoaffinity hypothesis proposed by Sperry (1963) posits that matching molecular gradients across the retina and tectum are sufficient to guide RGC axons to their topographically appropriate termination zone (TZ) in the OT/SC. Subsequently, Bonhoeffer and colleagues progressively refined a role for graded molecules in the control of topographic mapping through both theoretical (e.g., Bonhoeffer and Gierer, 1984) and experimental contributions. Among the most notable discoveries by Bonhoeffer was the first demonstration that graded repellent activities are major players in map development (Walter et al., 1987a,b; Baier and Bonhoeffer, 1992). His group went on to clone ephrinA5 (Drescher et al., 1995), and more recently Repulsive Guidance Molecule (RGM) (Monnier et al., 2002) as molecules responsible in part for this activity.

To date, ephrinA ligands and their EphA receptors are the best-studied molecules that meet criteria for topographic guidance molecules (Flanagan and Vanderhaeghen, 1998; O'Leary et al., 1999). EphAs are expressed by RGCs in a high to low, temporal to nasal (T-N) gradient, and ephrinAs (ephrinA2 and -A5) are expressed in an increasing gradient along the anterior-posterior (A-P) axis of the target (Cheng and Flanagan, 1994; Cheng et al., 1995; Connor et al., 1998; Drescher et al., 1995; Monschau et al., 1997). Consistent with these expression patterns, ephrinAs are repellents for RGC axons, and preferentially repel temporal axons (Nakamoto et al., 1996; Monschau et al., 1997; Frisen et al., 1998; Feldheim et al., 1998). Loss-of-function and gain-of-function analyses in mice have confirmed roles for EphAs and ephrinAs in mapping the T-N retinal axis along the A-P axis of the SC through a repellent mechanism (Frisen et al., 1998; Feldheim et al., 2000; Brown et al., 2000).

A primary role for graded guidance molecules in chick OT and rodent SC is to regulate topographic branching along RGC axons, a process that imposes unique requirements on the molecular control of map development (Yates et al., 2001). Initially, RGC axons overshoot their appropriate $\mathrm{TZ}$ along the A-P axis of the OT/SC. Topographically appropriate connections are established exclusively by branches that form interstitially along the axon shaft. Branches form with substantial A-P topographic specificity that is enhanced through the preferential arborization of appropriately positioned branches and elimination of ectopic branches (Yates et al., 2001). Because the development of topographic maps by growth cone targeting versus axon branching poses different requirements on their molecular control, these findings have substantial implications for the roles and limitations of ephrinAs and other potential guidance molecules in map development (Yates et al., 2001; McLaughlin et al., 2003a). For example, although ephrinAs inhibit branching along RGC axons posterior to their correct $\mathrm{TZ}$, this mechanism alone cannot account for topographic specific RGC axon branching, and consequently retinotopic mapping (Yates et al., 2001). Topographic branching requires additional graded molecular activities that inhibit or promote branching and cooperate with the ephrinAs expressed in the OT/SC.

Explanations of $\mathrm{T}-\mathrm{N}$ retinal mapping defects along the A-P SC axis in EphA and ephrinA mouse mutants have focused on the graded expressions of EphAs in the retina and ephrinAs in the SC. However, in both mice and chicks, ephrinAs are also expressed in the retina, in a gradient that opposes the EphA gradient, and EphAs are also expressed in the OT/SC, in an opposing gradient to that of the ephrinAs (Marcus et al., 1996; Connor et al., 1998; Hornberger et al., 1999). These countergradients could in principle regulate topographic branching. Consistent with this suggestion, overexpression of ephrinA2 in chick retina perturbs mapping (Hornberger et al., 1999). This finding has been interpreted as due to an enhancement of the $\mathrm{T}-\mathrm{N}$ gradient of functional EphA receptors in RGCs through ephrinA- mediated receptor inactivation (Hornberger et al., 1999). However, the presence of ephrinAs on RGC axons might also contribute to 
mapping by influencing axon-axon interactions and increasing both the amount of ephrinAs in the developing OT/SC and the slope of the overall ephrinA gradient (McLaughlin and O'Leary, 1999). In addition, ephrinAs may act as receptors because EphA: ephrinA binding appears to result in bidirectional signaling (Huai and Drescher, 2001; Knoll et al., 2001; Knoll and Drescher, 2002; Cutforth et al., 2003), suggesting that axon guidance activities can be transduced into RGC axons by both EphAs and ephrinAs. Repellent countergradients of EphAs and ephrinAs within the retina, particularly RGCs and the OT/SC, could account for the initial topographic bias in branching observed in vivo. In this scenario, OT/SC expressed ephrinA's signal through EphAs on RGC axons to inhibit branching along the axon shaft posterior to the topographically correct $\mathrm{TZ}$, whereas OT/SC expressed EphA's signal through ephrinAs on RGC axons to inhibit branching anterior to the correct $\mathrm{TZ}$ in the OT/SC.

Historically, models of topographic mapping were based upon the action of molecular activities that promote axon growth (see e.g., Fraser and Hunt, 1980). However, the identification by Bonhoeffer and colleagues of repellent activities in chick OT that differentially affect temporal and nasal RGC axons (Bonhoeffer and Huf, 1982; Walter et al., 1987a,b) has resulted in the incorporation of repellent activities into some more recent models of the guidance of RGC axons to their correct TZs (Gierer, 1983, 1987; Honda, 1998; Goodhill and Richards, 1999). These models have used a gradient determined parameter that is minimized or maximized to guide RGC axon growth cones to the correct OT location of their TZ (Gierer, 1983, 1987) or to stop RGC axons once this parameter reaches a threshold value (Honda, 1998; Goodhill and Richards, 1999). While provoking and potentially relevant to retinotectal map development in amphibians and fish, these models do not incorporate or explain fundamental features of map development in chick OT and rodent SC, including the initial overshoot of RGC axons, the subsequent topographic branching interstitially along the axon shaft, and later map refinement (McLaughlin et al., 2003a).

Here we present a computational model and simulations that replicate the primary features of retinotopic map development in chick and mice, most importantly topographic branching and map refinement. Our model shows that the topographic bias in initial branching can be accounted for by EphAs and ephrinAs expressed on RGC axons acting as receptors for ephrinAs and EphAs, respectively, expressed by OT/SC cells or any set of repellent countergradients that mimic the salient features. In addition, our model incorporates the progressive increases in the contribution of EphAs and ephrinAs expressed on RGC axons to the overall SC levels that likely occur as RGC axons arborize. This developmental increase in ephrinA repellent progressively restricts subsequent branching and arborization to topographically correct locations and causes the retraction of ectopic arbors and primary axons, resulting in considerable map refinement. However, to more closely replicate the in vivo scenario, we have incorporated in a refined model a process termed branchdensity that has features that resemble those thought to be contributed by patterned neural activity or a cellular mechanism with similar properties (see e.g., Shatz, 1990; Wong, 1999; Debski and Cline, 2002). The branchdensity parameter results in an increased level of refinement and TZs that closely resemble those seen in vivo. This computational model not only reproduces normal map development in chick OT and mouse SC, but also replicates the in vivo phenotypes of ephrinA deficient mice and Is12-EphA3 knockin mice, in which wildtype ephrinA/EphA signaling levels are decreased or increased, respectively.

\section{METHODS}

All simulations were performed using a custom program written for Matlab 6.0 run on a Dell 8250 Intel Pentium based computer. The retina and SC were divided into 100 segments each along the T-N and A-P axes, respectively, with three RGCs per retinal segment, 300 axons total. EphA and ephrinA levels were determined for each RGC according to its T-N position in the retina and the graphs shown for each simulation. For the EphA knockin simulation the wildtype and knockin RGC populations were assigned to alternating adjacent retinal segments, resulting in 150 wild-type and 150 knockin RGCs total.

The simulations began with RGC axons extended across the OT/SC, similar to the in vivo situation (Simon and O'Leary, 1992a,b; Yates et al., 2001). Two hundred iterations were performed for each simulation, except for the single gradient models that were simulated for 75 or 25 iterations. At the start of each iteration $(t)$, totalrepellent $\left(I^{T}\right)$ levels and the probability of branching, $p_{n}(y)$, were determined along the length of each RGC axon simulated. Secondary branches were formed along the length of existing branches with probability $p_{n}(y)$. For the chick wild-type simulation the values for the constant parameters were: $\omega=0.0034, \theta=11.7, \phi=1.0, \eta$ $=0.35, \alpha=0.7, \gamma=7, \beta=10, \rho=2.0$. For the mouse wild-type, ephrinA deficient, and Isl2-EphA3 knockin simulations the values for the constant parameters were: $\omega=0.0034$, $\theta=35.6, \phi=3.0, \eta=0.6, \alpha=0.7, \gamma=7, \beta=15, \rho=1.5$. For the first single gradient simulation the values for the constant parameters were: $\omega=0.000255, \theta=6.8, \phi=0.25$, $\eta=0.6, \alpha=0.7, \gamma=0, \beta=2.5, \rho=2.0$. For the single 
gradient simulations the values for the constant parameters were: $\omega=0.00102, \theta=5.6, \phi=1.0, \eta=0.6, \alpha=0.7, \gamma=0$, $\beta=10, \rho=2.0$.

Interstitial branches in vivo extend from the RGC axon shaft at approximate right angles; therefore, primary branches in the simulations were drawn extending from the RGC axon shafts at $90^{\circ}$ angles. The initial segment of a primary branch extended randomly either "up" or "down" from the RGC axon, but once established, additional segments added to that branch were added in the same direction. Higher order branches were drawn to extend from lower order branches at either a right angle or a $45^{\circ}$ angle, chosen randomly. In addition, the direction of the secondary branch was chosen randomly as either "left" or "right" and "up" or "down" for those at a $45^{\circ}$ angle. Once an angle and direction were established for a higher order branch all additional segments added to that branch were added in the same direction.

\section{RESULTS}

\section{Potential Mechanisms Controlling RGC Axon Mapping}

Topographic specific branching is the critical event in retinotopic map development in chick OT and mouse SC (see Introduction). Intuitively, a single gradient repellent model cannot account for topographic specific branching (see Fig. 14 in Yates et al., 2001). Nonetheless, as a prelude to the computational modeling and simulations of countergradients of repellents presented below, we simulated the action of a single gradient repellent model using a wide ranging set of parameters, including the same parameters used below for the retinally expressed EphA receptors and OT/SC expressed ephrinA ligands. We find no reasonable circumstances under which the single gradient model can recapitulate topographic map development for wild-type chicks or mice, or the aberrant maps described in mutant mice (data not shown).

Therefore, topographic specific branching requires not only the known repellent action of graded ephri$\mathrm{nAs}$ in the OT/SC, but also at least one other graded activity that cooperates with it to progressively restrict branching and develop a correct TZ (Fig. 14 in Yates et al., 2001). One such graded activity is a second repellent activity, distributed in a gradient that is opposite (i.e., counter) to the known ephrinA gradient. As described in the Introduction and Discussion, the EphAs and ephrinAs are expressed in countergradients within both the retina and the OT/SC and have the properties to act bidirectionally. This countergradient system is used for this model, although other repellent activities that meet the appropriate criteria could be substituted and/or involved. A countergradient repellent model also requires that RGC axons either have an intrinsic ability to branch along their length, or that external signals, such as BDNF, actively promote RGC axon branching and arborization (Cohen-Cory and Fraser, 1995; Choi and O'Leary, 1999; Cohen-Cory, 1999).

We assume that RGC axon branching exhibits a threshold response to increasing repellent activity [Fig. 1(A)]. In vitro studies show that RGC axons that extend up a gradient of increasing ephrinA repellent stop their forward extension once they reach a threshold level of ephrinA (Rosentreter et al., 1998). RGC axon branching in the chick also shows a large decrease in branching over a narrow range of ephrinA, also suggesting a threshold response (Yates et al., 2001). The combined signals from retinal EphA/OT ephrinA repellent binding and retinal ephrinA/OT EphA counter-repellent binding potentially allow for branching only at locations where total repellent is less than threshold [Fig. 1(A)]. Branching is topographically biased, as the minimum level of repellent occurs at the topographically correct TZ, but not precise, as threshold levels of repellent and counterrepellent are reached far posterior and far anterior of the $\mathrm{TZ}$, respectively.

As RGC axons arborize, they increase their total surface area of membrane. Because RGCs express ephrinAs in a high to low N-T gradient, and ephrinAs are found along RGC axons, it is reasonable to assume that as RGC axons arborize, the levels of ephrinAs in the OT/SC also increase in a low to high A-P gradient. Therefore, branching and arborization should add additional ephrinA repellent to the SC, increasing and steepening the OT/SC endogenous gradient of ephrinAs [Fig. 1(B)]. In addition, branching and arborization should add additional EphAs to the $\mathrm{OT} / \mathrm{SC}$ in a high to low A-P gradient. The initial levels of OT/SC-expressed repellents can result in topographic-specific branching, but the addition of repellent from progressively increasing branches and arbors may be necessary to drive the precise branching patterns and refinement observed at later stages of map development [Fig. 1(B)].

\section{Description of the Model}

Based on descriptions of the in vivo gradients of some ephrinAs and EphAs in the retina and OT/SC (Cheng et al., 1995; Drescher et al., 1995; Monschau et al., 1997; Frisen et al., 1998; Hornberger et al., 1999; Brown et al., 2000), we use exponential EphA and ephrinA gradients for our simulations. For simplicity 


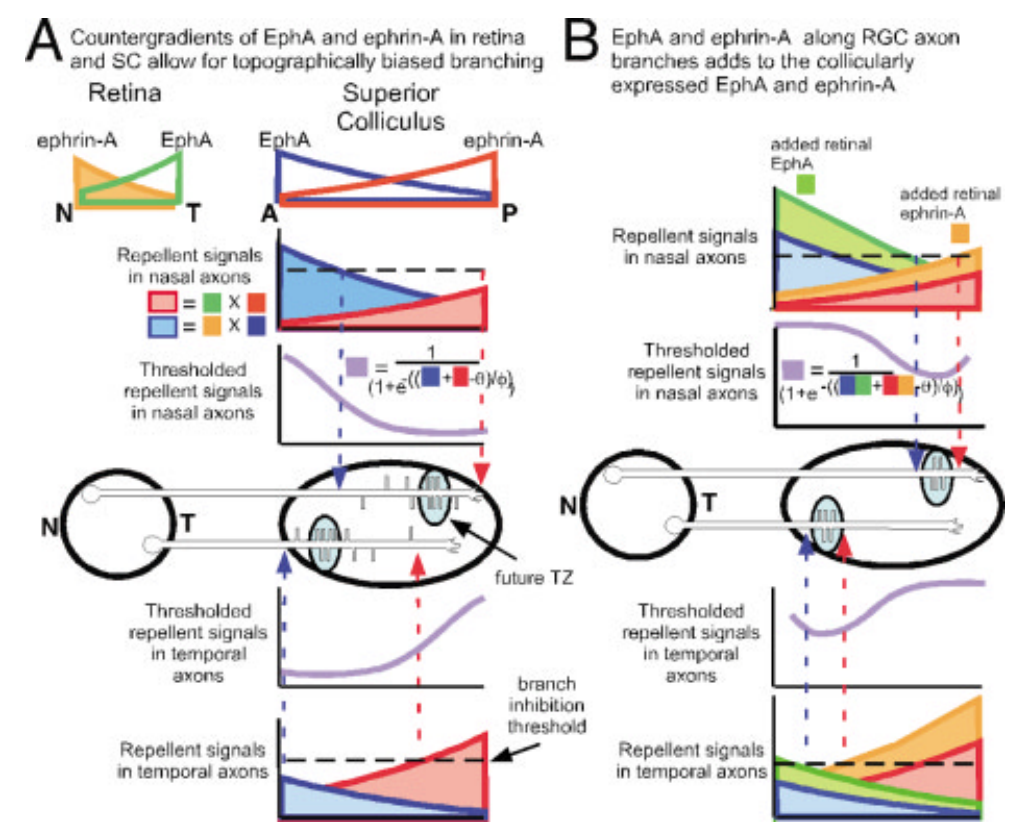

Figure 1 Countergradients of EphA/ephrinA in retina and SC can specify initial topographic branching. (A) EphA and ephrinA are expressed in opposing gradients in both retina and SC. Branching is shown for a nasal and temporal RGC axon. Posterior to the correct topographic site, repellent signaling increases due to higher levels of collicular ephrinA interacting with EphA receptor on RGC axons (shown in red). Anterior to the correct topographic site, counter-repellent signaling also increases due to higher levels of EphA collicular counter-repellent interacting with ephrinA counter-receptor on RGC axons (shown in blue). The highest amount of branching occurs around the topographically correct location in the SC as this is where the level of repellent + counter-repellent is lowest. Branching occurs both anterior and posterior to the TZ until repellent + counter-repellent signaling (red + blue) reaches a threshold (dashed line). We model repellent and counter-repellent signaling with a thresholded or sigmoidal function (purple line). This function causes signaling in the axon to increase rapidly as repellent or counter-repellent level nears threshold $\theta$. The rate at which repellent signaling increases anterior and posterior to the TZ is controlled by the slope of the sigmoid $\phi$. (B) Retinal axons arborize in the SC, causing repellent to be added from the arbors themselves as they express both EphA and ephrinA. The combination of addedrepellent (orange) and addedcounter-repellent (green) causes an increase in overall signaling, which leads over time to the threshold for branch inhibition being reached at the anterior and posterior border of the topographically correct TZ. This greatly diminishes branching outside of the TZ.

the various subtypes of EphAs and ephrinAs are combined into single EphA and ephrinA curves [Fig. $2(\mathrm{~A}, \mathrm{~B})]$. This is reasonable because ephrinA2 and ephrinA5 bind and activate all of the EphAs expressed by RGCs (EphA3, A4, A5, A6, A7 in chick; Cheng et al., 1995; Connor et al., 1998; EphA4, A5, and A6 in mice; Brown et al., 2000) and in the OT/SC with similar efficacy (Davis et al., 1994; Gale et al., 1996; Monschau et al., 1997). Generation of an evenly spaced mapping of the retina onto the OT/SC using axon repellents theoretically requires an inverse relationship between receptor and ligand pairs. This results in a minimum for the combination of repellent and counter-repellent signaling at the location of the topographically correct TZ [Fig. 1(A)], allowing for an initial weak bias in topographic branching. The added repellents due to branching and arborization must also have a minimum at the topographically correct TZ to maintain this one-to-one mapping; this minimum will be naturally achieved through the action of the countergradients in regulating initial topographic branching [Fig. 1(B)]. Thus, ligand and counterligand must also be inversely related. The EphA and ephrinA gradients chosen for this simulation fulfill these requirements [Fig. 2(A,B)].

The probability of branching, $p_{n}(y)$, (Equation 1) varies by SC position, $y$, along the length of axon $n$ according to two factors: repellent and counter-repellent ligands expressed in the SC and repellent and counter-repellent receptors expressed by RGCs and present along their axons and branches, which combine to form totalrepellent, defined as $I^{T}$ (Equation 2). 


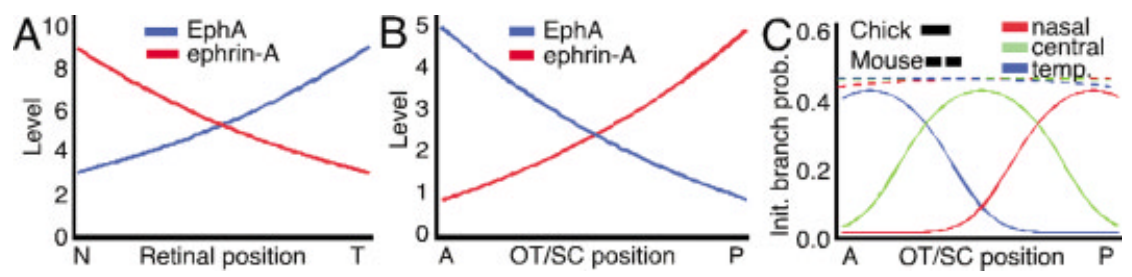

Figure 2 Wild-type levels of EphAs and ephrinAs in retina and OT/SC specify initial branch probabilities. (A) Graph of the inversely proportional exponential curves for EphA receptor and ephrinA counter-receptor across the nasal-temporal (N-T) axis of the retina used for the simulations. (B) Graph of the inversely proportional exponential curves for ephrinA ligand and EphA counterligand across the anterior-posterior (A-P) axis of the OT/SC used for the simulations. (C) Initial branch probability shown for three locations across the retina during simulations of chick retinotectal map development (solid lines) and mouse retinocollicular map development (dashed lines). At the start of the simulations there is a bias for branching at topographically correct locations.

$p_{n}(y)=\eta\left(1-1_{n}^{T}(y)\right)(\eta$ is a scaling constant)

Signals from OT/SC-expressed repellent and counterrepellent activities are determined based on receptorligand pairing using a mass action law with sigmoidal thresholding, as shown in Figure 2(C), (Equations $2-4)$, where $(R)$ is the EphA receptor and $\left(R^{C}\right)$ the ephrinA counter-receptor level present on RGC axons, branches, and arbors, and where $[L(y)]$ is the level of ephrinA ligand, and $\left[L^{C}(y)\right]$ the level of EphA counterligand expressed by cells in the OT/SC at location $y$.

The added repellent perceived by an RGC axon $n$ at location $y$ in the OT/SC is due to branches and arbors from other RGC axons and determined by the Eph receptor level of the axon $n$, the ephrinA counterreceptor level of the arbors from other axons $z$, and the size of those arbors at location $y$ (Equation 3). Totalarborsize $_{z}(y)$, defined as $S_{z}^{T}(y)$, is the sum of all branch segments extending from axons $z$ at SC location $y$, while $\omega$ scales the level of added repellent $\left(I^{A}\right)$ due to retinally expressed ligands. The added counterrepellent $\left(I^{\mathrm{AC}}\right)$ due to EphAs expressed on retinal arbors encountered by axon $n$ is determined similarly (Equation 4).

$$
\begin{gathered}
I_{n}^{T}(y)=\frac{1.0}{1+e^{-\left(R_{n}^{C} L^{C}(y)+I_{n}^{A C}(y)+R_{n} L(y)+I_{n}^{A}(y)-\theta\right) / \phi}} \\
I_{n}^{A}(y)=\omega \sum_{z}\left(R_{n} R_{z}^{C} S_{z}^{T}(y)\right) \\
I_{n}^{\mathrm{AC}}(y)=\omega \sum_{z}\left(R_{n}^{C} R_{z} S_{z}^{T}(y)\right)
\end{gathered}
$$

New branches form along the axon shaft with probability $p_{n}(y)$. Existing branches can extend, retract, or remain unchanged where $p_{n}(y)$ is the probability of extension, $\left(1-p_{n}(y)\right)^{2}$ is the probability of retraction, and $\left(1-p_{n}(y)\right) p_{n}(y)$ the probability of remaining unchanged. These probabilities result from the order in which these possibilities are evaluated, with extension considered first; failing that, retraction considered next; and finally, failing that, remaining unchanged. Only existing branches that are greater than three units in length are allowed to form secondary branches. Branches are only retracted if there are no secondary branches extending from the segment to be removed. The probability of the primary axon retracting at its distal end is determined by

$$
\begin{array}{rc}
p_{n}^{r}(y)=1-\rho\left(p_{n}(y)\right) & \text { for } 0 \leq \rho\left(p_{n}(y)\right) \leq 1, \\
p_{n}^{r}(y)=0 & \text { for } \rho\left(p_{n}(y)\right)>1 \\
& (\rho \text { is a scaling constant })
\end{array}
$$

The axon shaft, as with branches, can retract only if no branches extend from the segment of axon that is to be removed. It is possible that an axon will retract completely if branching is insufficient to establish a mature arbor.

\section{Wild-Type Map Development}

We model map development through a simulation of RGC axon branching within the OT/SC (Figs. 3 and 4). We begin each simulation with RGC axons extended across the OT/SC as found in vivo (Simon and O'Leary, 1992a,b; Yates et al., 2001; McLaughlin et al., unpublished observations). The retina and OT/SC are divided into 100 domains, each having progressively more or less EphA and ephrinA levels. Each retinal domain has three RGCs, resulting in $300 \mathrm{RGC}$ axons total extending across the A-P axis of the OT/SC. Simulations of 

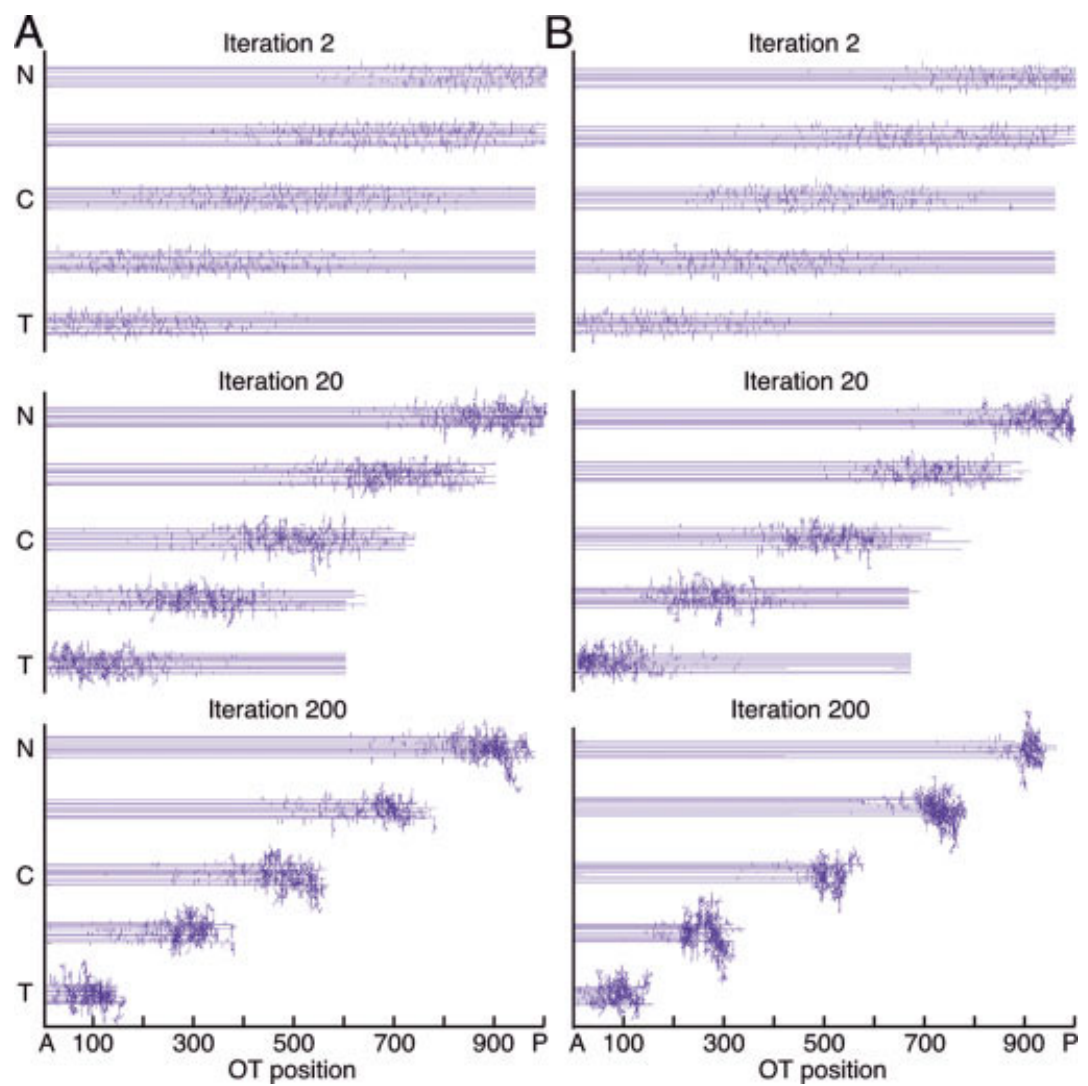

Figure 3 Simulations of chick retinotectal map development. (A) and (B) Ten RGC axons from five different retinal locations evenly distributed across the $\mathrm{T}-\mathrm{N}$ axis of the retina, with examples from three time points during the simulation. The axons shown in each iteration were chosen randomly within each retinal origin from the 300 axons simulated. (A) In simulations run without the branchdensity parameter, branching is somewhat diffuse at the start of the simulation (iteration 2), but with a clear topographic bias for the area around the correct TZ. As RGC axons arborize, added repellents from these arbors restrict branching to more topographically correct locations, eventually resulting in the retraction of the RGC axon overshoot and the formation of a mature TZ in the correct location (iteration 200). Note that some ectopic branches remain. (B) Simulations run utilizing the branchdensity parameter also have somewhat diffuse branching at early time points. However, at iteration 200, a dense, focused TZ is evident in the correct location with very few ectopic branches remaining. $\mathrm{C}$, central; $\mathrm{N}$, nasal; $\mathrm{T}$, temporal. [Color scheme can be viewed in the online issue, which is available at www.interscience.wiley.com.]

wild-type mapping in chick and mouse were initially run with and without the added repellents contributed by RGC axon branches and arbors. Because we found that topographic order at mid and late stages of map development is substantially diminished in simulations run without the added repellent parameters (data not shown), we present here only simulations in which it is included in the computations. In addition, to simplify the presentation, we have chosen to show only three of the 200 progressive iterations run for each simulation; these three iterations (iterations 2, 20, and 200) are representative of early, mid, and late stages of map development.

The initial probability of branching is due entirely to the OT/SC-expressed repellent and counter-repellent [Fig. 2(C)]. Initial branch specificity is different between rodents and chick, with initial branching in the rodent SC being less topographic than the relatively strong specificity observed in chick OT (Simon and O’Leary, 1992a,b; Yates et al., 2001).

Chick. We first describe simulations of map development in chick OT using 200 progressive iterations of branching events [Fig. 3(A)]. Branching patterns are shown for sets of 10 RGC axons from five retinal locations equally spaced across the $\mathrm{N}-\mathrm{T}$ axis. The simulation closely resembles the in vivo time course of map development in chick OT (Yates et al., 2001). 

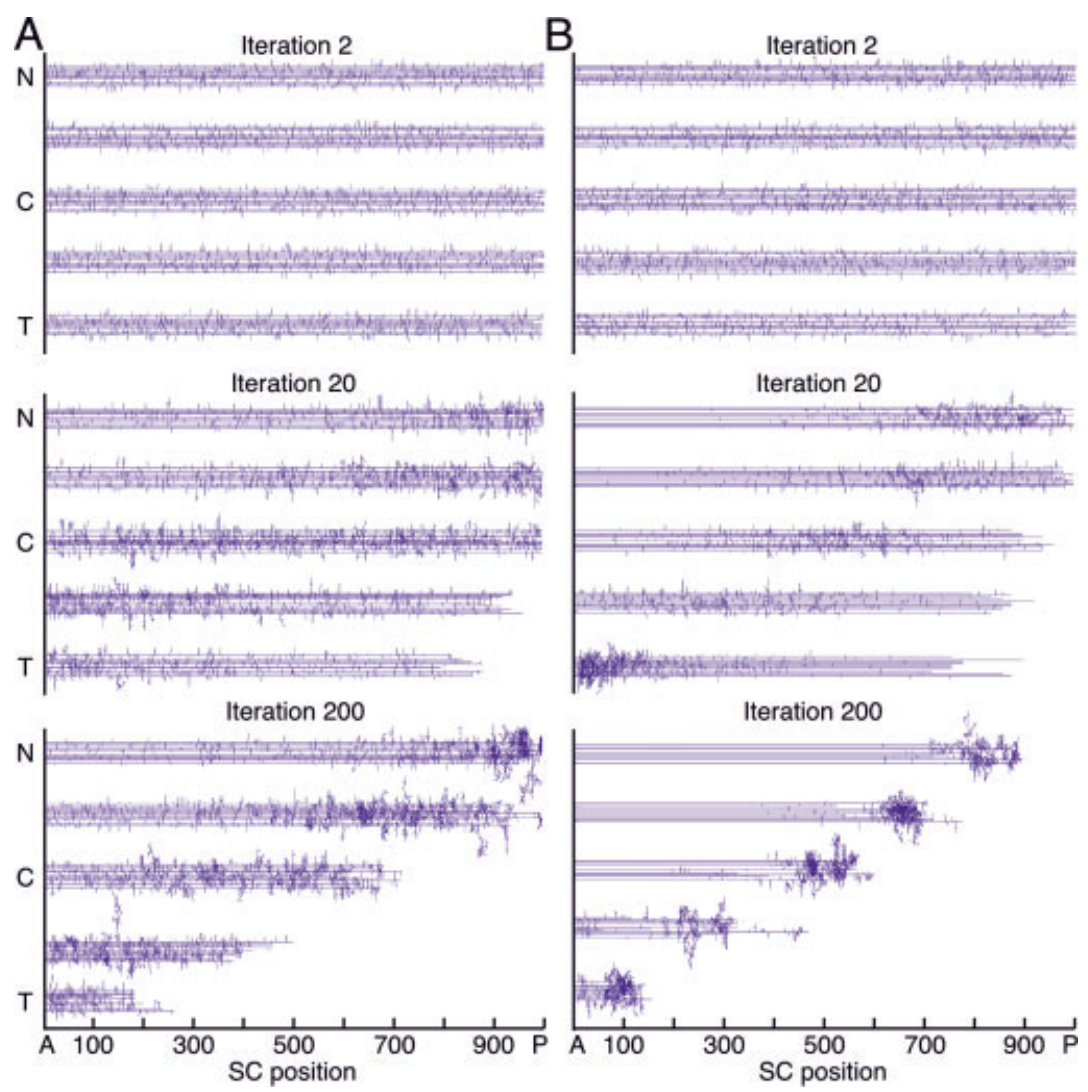

Figure 4 Simulations of mouse retinocollicular map development. (A) and (B) Ten RGC axons from five different retinal locations evenly distributed across the T-N axis of the retina, with examples from three time points during the simulation. The axons shown in each iteration were chosen randomly within each retinal origin from the 300 axons simulated. (A) In simulations run without the branchdensity parameter, branching is initially diffuse across the entire anteriorposterior (A-P) axis of the SC, though slightly biased for the correct $\mathrm{TZ}$, as in vivo (iteration 2). Branching is significantly more diffuse at the start of the simulation compared to the chick simulation. As retinal axons arborize, added repellents on these arbors restricts branching to more topographically correct locations, resulting in the elimination of the RGC axon overshoot. However, though the topographic specificity of branching has increased substantially by iteration 200 a dense TZ does not develop. Many RGC axons still have ectopic arbors outside of the TZ. (B) Simulations run utilizing the branchdensity parameter also have diffuse branching across the SC at early time points. However, at iteration 200, a dense, focused TZ is evident in the correct location with very few ectopic branches remaining. [Color scheme can be viewed in the online issue, which is available at www.interscience.wiley.com.]

At an early stage [e.g., Fig. 3(A), iteration 2], branch distribution has a topographic bias for the correct A-P location of the future TZ. By iteration 20, this bias becomes much stronger due to both the preferential addition of branches around the site of the future TZ as well as a net removal of ectopic branches. This progressive process continues such that by iteration 200 a clearly defined TZ has emerged at the appropriate A-P location, although some branches remain evident at ectopic sites along the axons. In addition, by this stage of the simulation, the overshooting segments of the primary axons have been eliminated. The initiation of this process of axon retraction is evident as early as iteration 20 .

Mouse. We next carried out simulations of map development in mouse SC as we did for chick OT [Fig. 4(A)]. Although the simulation captures some features of normal map development in mouse SC, it does not result in a sharply defined TZ as in the chick simulation. At an early stage [Fig. 4(A), iteration 2], branches are broadly distributed across the A-P axis of the SC, but do exhibit a slight topographic bias. By iteration 20, this bias becomes 
stronger, principally due to the preferential addition of branches around the site of the future TZ. By iteration 200 a broad TZ is loosely focused around the appropriate A-P location, and many branches remain evident at ectopic sites along the axons. Although topographic order is coarse, the overshooting segments of the primary axons have been largely eliminated. Thus, at early stages, this simulation resembles the early weak topographic bias in branching normally observed in vivo, but the tightly focused $\mathrm{TZ}$ and highly ordered projection fail to emerge.

\section{Modeling and Simulations with an Added Parameter Termed Branchdensity}

The simulations described above show that countergradients of repellent activities alone can drive map development to a high degree of topographic order. However, the maps, particularly those in the mouse SC simulations, do not fully develop the high degree of topographic precision observed in vivo. Therefore, to more faithfully reflect the in vivo scenario, we have repeated the simulations with another parameter added, termed branchdensity ${ }_{n}(y)$, defined as $D_{n}(y)$ (see Discussion for potential biological correlates). In the simulations, higher order branches can form along existing branches, thus sections of the axon that have large numbers of branches have a proportionally greater likelihood of adding new branches during subsequent iterations compared to sections of the axon with low amounts of branching. The branchdensity parameter nonlinearizes this process, resulting in a further enhancement of branching at locations along the axon with a high number of existing branches (Equations 5 and 6).

Branchdensity $_{n}(y)$ is calculated individually for each axon according to the branch distribution along only that axon, independent of the branch distribution along any other axon. We used a Gaussian weighted branch density over $20 \%$ of the axon shaft, where $\sigma_{z}$ are constants from this Gaussian filter with standard deviation of 10. This results in an enhancement of branching not limited to a given segment of the initial 100 axon segments, but also to nearby segments. At early iterations $(t)$, when there are few branches, branchdensity has little influence on the branching process. The contribution of branchdensity was strengthened at later iterations of the simulations as shown (Equation 5):

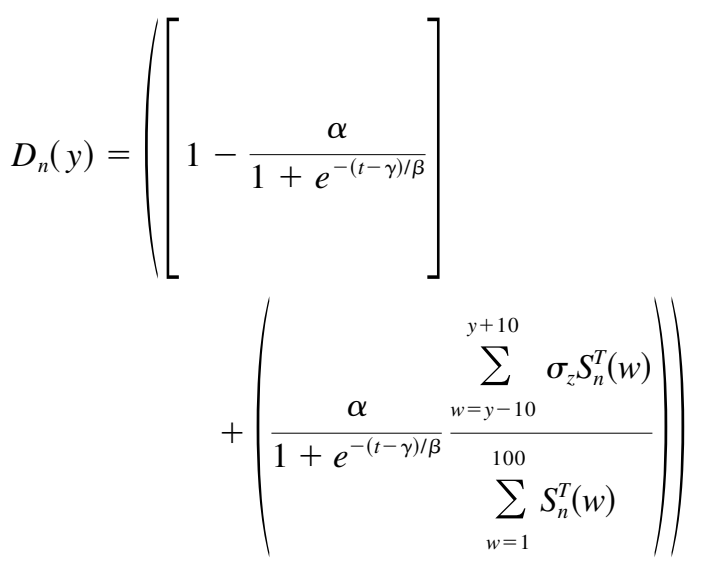

( $\alpha, \beta, \gamma$ are constants).

As shown in Equation 6, the branchdensity parameter serves to increase the probability of an individual RGC axon branching in locations where it has already branched:

$$
p_{n}(y)=\eta\left(1-I_{n}^{T}(y)\right) D_{n}(y)
$$

Chick Simulation with the Branchdensity Parameter. We repeated simulations of map development in chick OT, again using 200 progressive iterations of branching events, but with the branchdensity parameter added [Fig. 3(B)]. At early and mid stages, branch distributions obtained in simulations done with and without the branchdensity parameter are essentially indistinguishable [compare Fig. 3(A) and (B), iterations 2 and 20]. By late stage, the simulation run with the branchdensity parameter exhibits a modest increase in topographic order compared to that run without the added parameter, which already has a high degree of topographic order. The main difference between the two simulations is the loss of the relatively small proportion of ectopic branches that persist in simulations run without the branchdensity parameter [compare Fig. 3(A) and (B), iteration 200].

The initial probability for branching, $P_{n}(y)$ specified by OT repellent, peaks at the TZ [Fig. 5(A)]. However, as map development progresses, the additional repellent due to branching and arborization results in sharply focused peaks of branching probability centered on the appropriate TZ [Fig. 5(A)]. Concurrent with this change, the initial topographic bias in branching is strongly enhanced and shows a sixfold increase in branch specificity between the first and last iterations of the simulation [Fig. 5(B)]. Analysis of total branch length shows that it rises quickly at the start of the simulation and eventually levels out as higher amounts of axonal repellent begin to restrict further branching [Fig. 5(C)]. Over the later iterations, 

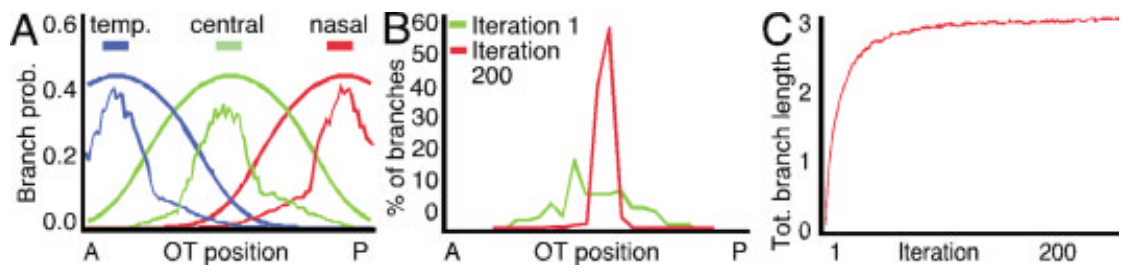

Figure 5 Changes in branch probability, branch distribution, and branch length throughout simulations of chick retinotectal map development. (A) Graph depicting branch probability for a chick map development simulation using the branchdensity parameter. The initial branch probabilities are shown for three retinal positions (heavy upper lines, iteration 1). Branch probability decreases during map development, and becomes more topographically biased as a result of added repellents from branches and arbors themselves (thin lower lines, iteration 200). (B) The actual branch distribution shown for all axons originating from central retina at the beginning (iteration 1) and end (iteration 200) of a simulation run using the branchdensity parameter. At iteration 1 branches are widely distributed across the OT, though biased for mid-OT (green). At iteration 200 the branch distribution peaks at the position of the TZ (red). (C) Total branch length (total length of all branches present at each iteration) is calculated after each iteration during the simulation and graphed. Total branch length rises quickly at the start of the simulation and eventually levels out, as higher amounts of added repellents restrict branching further. Note that despite the essentially stable overall total branch length from relatively early time points, topographic branch specificity continues to increase. This suggests branches at latter stages are removed from ectopic locations and replaced by branches formed at more topographically correct locations, thus maintaining close to net zero change in total branch length. In addition, total branch length increases negligibly at later stages indicating that the simulation is stable. [Color scheme can be viewed in the online issue, which is available at www.interscience.wiley.com.]

topographic specificity continues to increase although total branch length remains constant. This indicates an equilibrium of overall branch length, suggesting that branches continue to form along the axon but that at later stages the rate of branch elimination from ectopic locations is enhanced compared to that at correct locations, resulting in no net change in total branch length. Thus, the refined map is stable.

\section{Mouse Simulation with the Branchdensity Param-} eter. Simulations of map development in the mouse SC without the branchdensity parameter resulted in a topographically ordered projection [Fig. 4(A)], but it lacks the sharp refinement characteristic of the in vivo map. We repeated simulations of map development in mouse SC with the branchdensity parameter added, which resulted in a sharply refined TZ as observed in vivo [Fig. 4(B)]. At early stages, branch distributions obtained in simulations done with and without the branchdensity parameter are essentially indistinguishable [compare Fig. 4(A) and (B), iteration 2]. By mid stage, though, the simulation run with the branchdensity parameter exhibits a modest increase in topographic order compared to that run without the added parameter. By late stage, the differences were significant between the two sets of simulations. In simulations run with the branchdensity parameter, virtually all ectopic branches are eliminated and the TZ is tightly focused at the correct A-P site [compare Fig. 4(A) and (B), iteration 200].

In summary, these results from modeling and simulations indicate that the endogenous EphA and ephrinA gradients are sufficient to direct initial topographic branching and that the added ephrinA and EphA repellent from RGC axon arbors can enhance topographic branching and help drive much of the refinement, resulting in the wild-type map. The addition of the branchdensity parameter enhances the precise specificity of the map, particularly in mouse SC, resulting in an ordered map that resembles that in vivo at all stages of development.

Because the branchdensity parameter is required to generate sharply focused TZs as seen in vivo, for the following simulations of ephrinA deficient mice and Isl2-EphA3 knockin mice, we present simulations that use this parameter.

\section{Retinotopic Map Development in EphrinA Deficient Mice}

Analyses of mice deficient for ephrinA2, -A5, or both (Frisen et al., 1998; Feldheim et al., 2000), show that ephrinAs are required for proper mapping of the T-N retinal axis along the A-P SC axis. To simulate the requirements of ephrinAs in map development, we 

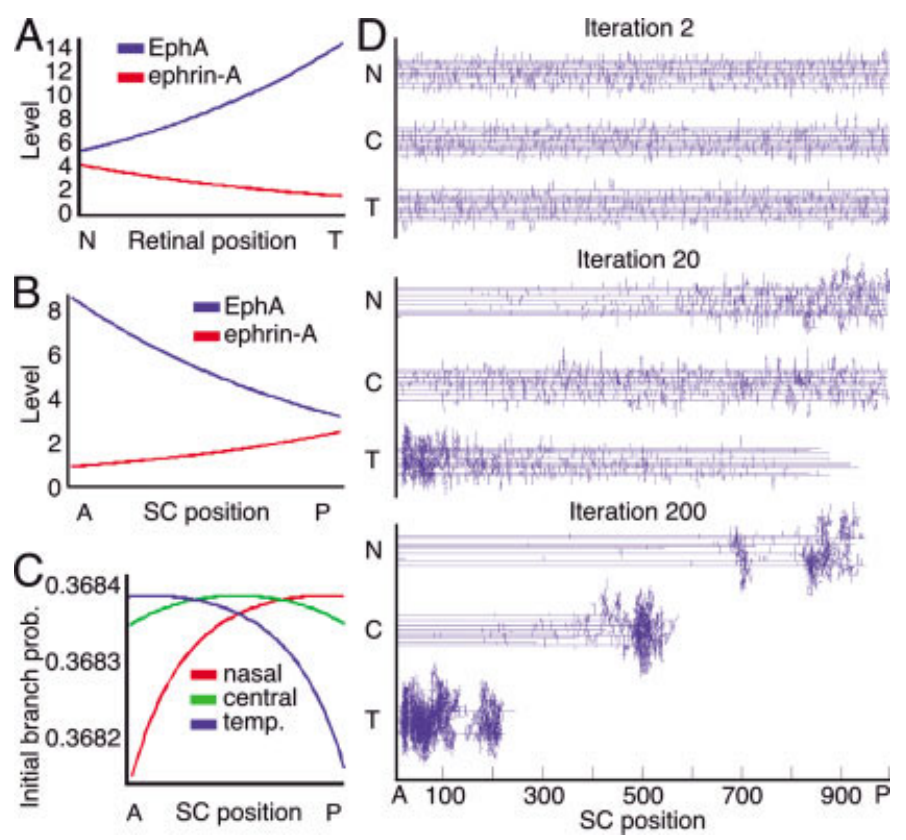

Figure 6 Simulation of retinocollicular map development for an ephrinA deficient mouse. (A) and (B) Exponential curves for EphA and ephrinA across the (A) nasal-temporal (N-T) axis of the retina and (B) anterior-posterior (A-P) axis of the SC for simulations of ephrinA deficient mice. EphrinA curves are reduced by $50 \%$ in retina and SC of ephrinA mutants, compared to wild-type, reflecting the continued presence of ephrinAs but at a diminished level, as in an ephrinA single mutant mouse. EphA levels are increased compared to wild-type, due to decreased receptor inactivation by ephrinA in the knockout. (C) Branch probability shown from three locations across the retina. At the start of the simulation there is only a slight bias for branching in topographically correct locations. (D) Simulation of an ephrinA deficient mouse, with examples at three time points during the simulation. Branching along 300 RGC axons was simulated for 200 iterations with branching patterns shown for 10 axons chosen randomly from three different retinal locations (nasal, $\mathrm{N}$; central, $\mathrm{C}$; temporal, T). Early in the simulation there is essentially no topographic bias in branching along RGC axons (iteration 2). However, as arborization proceeds a topographic bias is quickly established and a TZ becomes evident (iteration 20). At the end of the simulation a topographically appropriate $\mathrm{TZ}$ has formed for all retinal locations. However, in addition to an appropriately located TZ, nasal and temporal RGCs maintain elaborate ectopic arbors anterior and posterior to their correct TZ, respectively, similar to phenotypes reported for ephrinA single mutants (Frisen et al., 1998; Feldheim et al., 2000).

have roughly approximated an ephrinA single knockout condition by halving the retinal and SC ephrinA gradients [Fig. 6(A,B)]. We also increase retinal and SC EphA levels, reflecting the presumed decreased inactivation of functional Eph receptors by ephrinA in both retina and SC, as occurs in vivo (Hornberger et al., 1999). No other changes are made from the previous wild-type mouse simulations done with the branchdensity parameter.

In the simulations with diminished ephrinA levels, branch probability still peaks at the A-P location of the topographically correct $\mathrm{TZ}$, providing each axon a very slight topographic bias for branching at the location of its future TZ [Fig. 6(C)]. Thus, although nasal and temporal RGC axons form branches along the entire A-P axis of the SC, initial branching has a slight topographic bias [Fig. 6(C)]. By mid stage, when the contribution of the axonal repellent becomes evident in wild-type simulations, a topographic bias in branching and early arborization begins to emerge [Fig. 6(D), iteration 20]. At late stage, well-defined arbors are evident at topographically appropriate and ectopic locations along the A-P axis [Fig. 6(D), iteration 200]. Temporal axons form a densely focused $\mathrm{TZ}$ at the appropriate A-P location, as well as ectopic arbors posterior to their correct TZ- this finding resembles that reported for both the ephrinA2 and -A5 single mutants (Frisen et al., 1998; Feldheim et al., 2000). In the simulation, nasal RGC axons form a TZ near their appropriate A-P location as well as ectopic arbors anterior to it. This finding resembles that reported for the ephrin-A5 knockout mouse (Feldheim et al., 2000). 


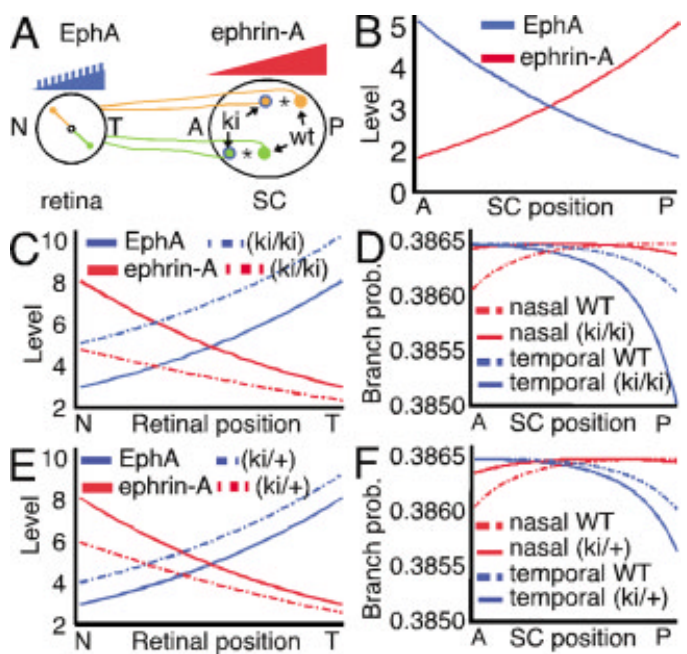

Figure 7 EphA and ephrinA distributions in Is12-EphA3 knockin mice. (A) In EphA3 knockin mice, EphA3 is expressed at an elevated level in half of all RGCs distributed across the retina, while the remaining half express their normal wild-type EphA levels. These two populations form separate but overlapping topographic maps, with the knockin (ki) RGC axons forming TZs shifted anteriorly and wild-type RGC axons (wt) mapping to more posterior locations. Asterisks mark the correct TZ for wild-type RGCs in wild-type mice. The shift in the map of the heterozygous knockin is half that of the homozygous knockin; the wild-type and knockin maps collapse into a single TZ for temporal RGC axons in anterior SC. (B) Inverse exponential curves showing the level of EphA and ephrinA in the SC of EphA3 knockin mice. These curves are the same as in wild-type animals. (C) Curves for EphA and ephrinA across the nasal-temporal (N-T) axis of the retina of homozygous EphA3 knockin mice (ki/ki). The wild-type population of RGCs (solid lines) has the same EphA and ephrinA levels as wild-type. The knockin population of RGCs has a gradient of EphA that is elevated compared to wild-type, and a functional gradient of ephrinA that is reduced compared to wild-type due to increased receptor inactivation (dashed lines). The EphA level is increased by a constant amount (25\% of the maximum EphA level in wild-type RGCs) in all knockin RGCs. (D) Initial branch probability shown for nasal and temporal wild-type RGC axons (solid lines). Note that the peak initial branch probabilities for homozygous knockin RGC axons (dashed lines) are shifted anteriorly compared to wild-type. (E) Curves for EphA and ephrinA across the nasal-temporal (N-T) axis of the retina of heterozygous EphA3 knockin mice (ki/+). The wild-type population of RGCs (solid lines) has the same EphA and ephrinA levels as wild-type. The knockin population of RGCs has a gradient of EphA that is elevated compared to wild-type, and a functional gradient of ephrinA that is reduced compared to wild-type due to receptor inactivation (dashed lines). The EphA level is increased by a constant amount $(50 \%$ of the EphA level added in homozygous knockin RGCs) in all knockin RGCs. (F) Initial branch probability shown for nasal and temporal wild-type RGC axons (solid lines). Note that the peak initial branch probabilities for heterozygous knockin RGC axons (dashed lines) are shifted slightly anterior compared to wild-type.

\section{Retinotopic Map Development in EphA3 Knockin Mice}

Homozygous Knockin Mice. In Isl2-EphA3 knockin mice, EphA receptor expression is increased in Isl2expressing RGCs, which account for about half of all RGCs scattered across the retina, while the other RGCs maintain their wild-type EphA expression levels (Brown et al., 2000). These two populations of RGCs have distinct gradients of EphAs, each being high to low along the T-N axis, but with the EphA3 knockin population at a higher overall level [Fig. 7(A)]. The two populations form distinct, partially overlapping maps, with the EphA3 knockin population compressed anteriorly and the wild-type RGC population compressed posteriorly within the SC [Fig. 7(A)] (Brown et al., 2000).

The expression of EphAs and ephrinAs in the EphA3 knockin mice is unaffected in the SC [Fig. 7(B)]. To simulate changes in RGC expression in the knockin mice, retinal EphA receptor levels are increased by a constant amount in half of the RGCs (termed knockin RGCs) and maintained at wild- type levels in the other RGCs (termed wild-type RGCs) [Fig. 7(C)]. Retinal ephrinA levels are also decreased in the knockin RGCs to account for potential inactivation of ephrinAs by EphA binding, and therefore a presumed decrease in the functional pool of ephrinAs in the affected knockin RGCs [if the phenomenon of EphA inactivation by ephrinAs described by Hornberger et al. (1999) occurs bidirectionally]. No other parameter changes are made from the wild-type simulation done with the branchdensity parameter. The diminished ephrinA levels cause the locations for the peak initial branching probability for knockin RGC axons to shift anteriorly compared to the wild-type RGCs due to increased repellent signaling [Fig. 7(D)]. The wild-type RGCs have their peak initial branching probability at the topographically correct TZ [Fig. 7(D)].

In simulations of the homozygous knockin, we find that initial branching resembles that observed in wildtype simulations with only little topographic bias, and the knockin and wild-type RGC populations overlap across the entire A-P SC axis [Fig. 8(A), iteration 2]. By mid stage [Fig. 8(A), iteration 20], a distinct order becomes evident in the branching patterns, and the branching patterns exhibited by the two RGC populations begin to separate from one another. By late stage [Fig. 8(A), iteration 200], the two populations have formed separate, distinct TZs. The shift between wild-type and knockin populations varies, with nasal knockin RGCs shifted by approximately $40 \%$ of the A-P axis of the SC and temporal RGCs shifted some- 

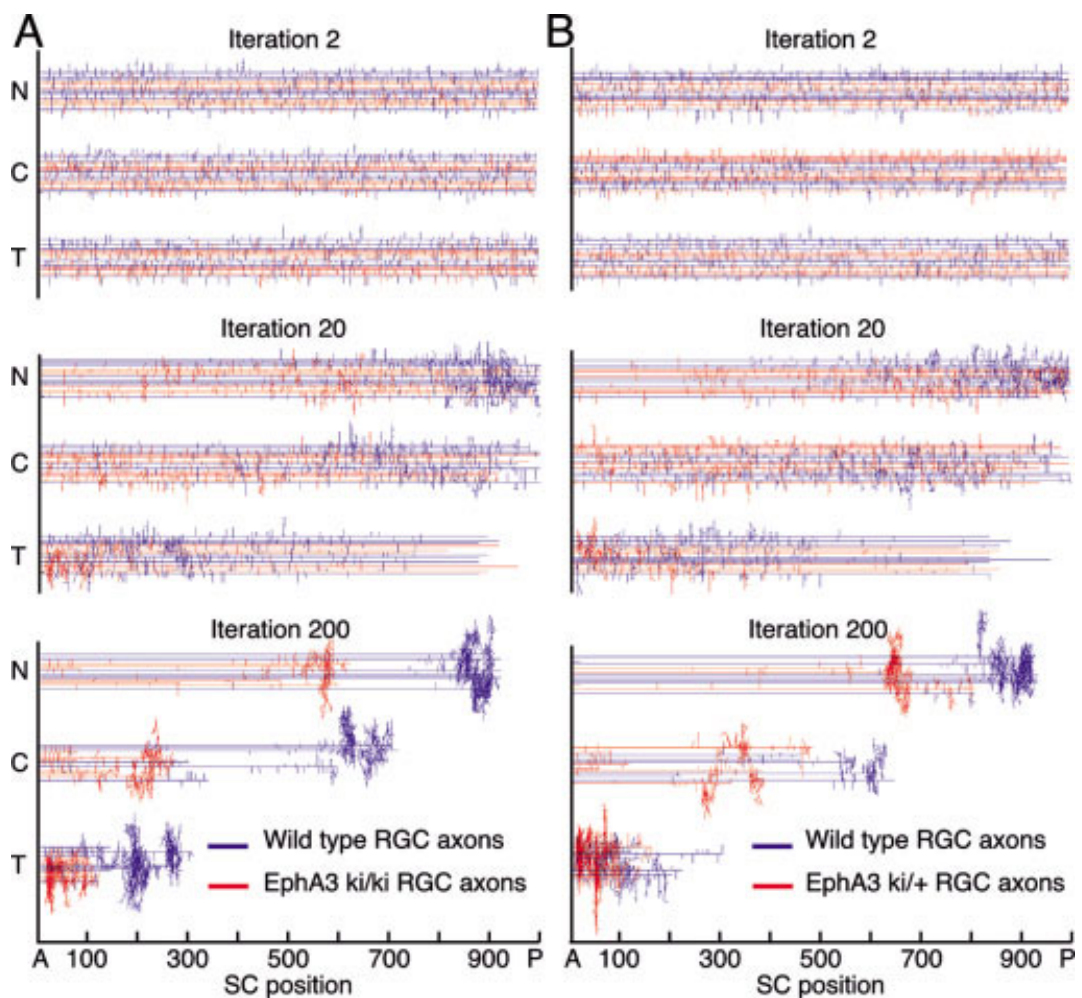

Figure 8 Simulations of mouse retinocollicular development in Is12-EphA3 knockin mice. (A) and (B) Twelve RGC axons (six wild-type RGC axons in blue, and six knockin RGC axons in red) from three time points (iterations) of mouse retinocollicular development. Axons are from three different retinal locations (nasal, $\mathrm{N}$; central, $\mathrm{C}$; temporal, $\mathrm{T}$ ), evenly distributed across the T-N axis of the retina. The axons shown in each iteration were chosen randomly for each retinal origin from the 300 axons simulated. (A) Map development in homozygous EphA3 knockin mice. Branching initially shows little topographic specificity with wild-type and knockin RGC axon branches widely dispersed across the SC (iteration 2). However, by iteration 20 the emerging TZs become evident. Branching for knockin RGC axons is shifted anteriorly due to their elevated EphA levels, compared to their wild-type neighbors. Branches for wild-type axons are shifted posteriorly as branches from knockin RGCs repel them from anterior positions. By iteration 200 a mature map is evident. Wild-type RGC axons have formed TZs in positions posterior to their correct topographic location. Knockin RGCs have formed TZs anterior to their correct topographic location. (B) Map development in heterozygous EphA3 knockin mice. Branching shows little topographic specificity initially (iteration 2) and even at iteration 20 there is a high degree of overlap in branches from wild-type and knockin RGCs. By iteration 200 a mature map is evident with the TZs for nasal and central knockin RGC axons shifted anteriorly compared to their wild-type counterparts. Temporal wild-type and knockin RGC axons form a single overlapping TZ in the appropriate topographic location in anterior SC. These results closely resemble the reported homozygous and heterozygous phenotypes in vivo (Brown et al., 2000).

what less, as observed in vivo (Brown et al., 2000). Central RGCs do not arborize at their topographically appropriate location at the midpoint of the A-P SC axis; instead the wild-type RGC arbors are shifted posteriorly and the knockin RGC arbors are shifted anteriorly, as found in vivo (Brown et al., 2000). Elimination of the posterior segments of overshooting RGC axons occurs normally, with the axons retracting to the point of a sustaining arbor [Fig. 8(A), iteration 200].
Each map is topographically organized according to its EphA/ephrinA levels and they partially overlap [compare final TZ positions in Fig. 8(A), iteration 200, relative to EphA receptor level from Fig. 7(C)]. Initially, wild-type RGCs have their peak branching probability at the topographically correct TZ, as specified by SC repellent. However, during the simulation their final TZs shift posteriorly due to the increase in axonal repellents from RGC axon branching and arborization of knockin RGC axons, whose branching 
shifts anteriorly due to their increased level of EphAmediated repulsion. Indeed, in simulations of the EphA3 knockin run without the contribution of axonal repellent (addedrepellent, addedcounter-repellent), the wild-type RGCs map across the entire A-P axis of the SC (data not shown). These findings indicate that the added repellents from RGC branches and arbors are a prominent influence on RGC mapping and the location of their TZs, as previously suggested (McLaughlin and O’Leary, 1999).

Heterozygous Knockin Mice. The model also replicates the phenotype of heterozygous EphA3 knockin mice (Brown et al., 2000). EphA3 and ephrinA levels are adjusted as before but with only half the added EphA3 to knockin RGCs compared to the homozygous simulation [Fig. 7(E)]. Similarly, retinal ephrinA levels are decreased a small amount in the knockin RGCs to account for receptor inactivation. These changes cause the locations for peak initial branching probability for knockin RGC axons to shift anteriorly compared to the wild-type RGCs, but to a lesser degree than in the homozygous knockins, whereas the wild-type RGCs have their peak initial branching probability at their topographically correct TZ [Fig. 7(F)].

Simulation results show an anterior shift in the TZs of knockin RGCs and a posterior shift in the TZs of wild-type RGCs, but to a lesser degree than in the homozygous knockin [Fig. 8(B)]. As in vivo (Brown et al., 2000), this results in less separation between the TZs formed by the wild-type and knockin RGCs in the heterozygous than in the homozygous knockin. For example, for central RGCs, the separation between the knockin and wild-type RGC TZs is approximately $40-50 \%$ of the A-P axis in the homozygous knockin, but only about $20 \%$ in the heterozygous knockin. In addition, the map collapses into a single map, or TZ, for RGCs from peripheral temporal retina [Fig. 8(B), iteration 200], as observed in vivo (Brown et al., 2000). We had previously interpreted this collapse into a single $\mathrm{TZ}$ as due to the smaller relative difference in EphA levels between wild-type and heterozygous knockin RGCs originating from more temporal locations in the retina. However, the model suggests that the collapse of the heterozygous map into a single $\mathrm{TZ}$ in anterior $\mathrm{SC}$ is due in part to the larger contribution of SC repellent to the total level of repellent compared to that in the homozygous. This added feature tends to maintain the wild-type RGC population at their topographically correct positions.

\section{DISCUSSION}

The computational modeling and simulations presented here recapitulate the sequential stages of map development observed in the developing chick OT and rodent SC (Nakamura and O'Leary, 1989; Simon and O'Leary, 1992a,b; Yates et al., 2001). In addition, the same computational model that directs proper map development also generates a reasonable facsimile of the distinct mapping phenotypes described in ephrinA deficient mice (Frisen et al., 1998; Feldheim et al., 2000) and Isl2-EphA3 knockin mice (Brown et al., 2000). This modeling and associated simulations also suggest several important features of map development. First, they show that a simple set of exponential, counter-repellent molecular gradients can establish a substantial degree of topographic order in the retinal projection to the OT/SC. The exact slope and magnitude of the gradients are not critical; instead the relationship of the gradients to one another is the crucial parameter. Second, they indicate that a considerable degree of topographic order can develop under the exclusive control of graded molecular activities that restrict branching to generate topographic specificity, as well as generate a considerable degree of refinement, ranging from elimination of a substantial proportion of ectopic branches to RGC axon retraction. Third, repellents found on RGC axon branches and arbors make a substantial contribution to map development, in particular to refinement seen at later stages. And fourth, the development of a sharply focused TZ resembling that found in vivo requires an additional parameter (termed branchdensity) that enhances branching along an individual axon near sites of previous branching along that given axon. The branchdensity parameter could have a number of biological correlates, including patterned neural activity in RGCs (Shatz, 1990; Wong, 1999; Debski and Cline, 2002), competition for a limiting, branch-promoting factor, or other competitive molecular interactions between RGC axons and branches with a molecular or cellular basis that enhance the probability of continued local branching. Axon branches may also compete for limited synaptic space (reviewed in Goodhill and Richards, 1999).

This model demonstrates that RGC axon-axon interactions can drive topographic map development and refinement. Early experimental work by Bonhoeffer and colleagues performed both in vivo (Thanos et al., 1984) and in vitro (Bonhoeffer and Huf, 1985) suggested a role for axon-axon interactions in chick retinotectal mapping. Our model indicates that countergradients of SC expressed repellents can establish 
an initial topographic bias in branching, because for any RGC population the level of branch inhibition is lowest at the A-P location of their future TZ. However, OT/SC repellents alone cannot generate the dramatic increase in topographic specificity of branching observed during map refinement. Simulations of both normal chicks and wild-type mice suggest two forces drive map refinement: added repellents (combination of addedrepellent and addedcounter-repellent parameters) from RGC axon branches and arbors that increase progressively with time; and the branchdensity parameter that nonlinearly enhances branching along an RGC axon near locations where branch number along that axon is highest.

An important feature revealed by the simulations is that fundamental aspects of map development emerge within the context of the model, although they are not mathematically formulated in it. For example, the model does not have a parameter programmed into it that directly describes the coarborization of neighboring RGCs, but axonal interactions that develop secondarily as the simulation progresses drive coarborization. The added repellents from RGC branches and arbors cause neighboring RGC axons to arborize together because the level of repulsion is least amongst axons that come from neighboring locations in the retina. The nonlinear/sigmoidal aspect of the added repellents further enhances this tendency, and results in a sharp increase in RGC branch and arbor repulsion both anterior and posterior to the correct TZ. The branchdensity parameter is calculated individually for each axon according to the branch distribution along only that axon, but because of the added repellents parameter it contributes to local axon-axon interactions and topographic specificity in refinement.

A principle role of ephrinAs in map development is to regulate $\mathrm{RGC}$ axon branching, and specifically to prevent branching and subsequent arborization posterior to the topographically correct location of the future TZ. However, for proper map development, additional information is required to prevent branching anterior to the correct TZ. A number of mechanisms could potentially explain the observed topographic specific branching, each including an additional graded activity that cooperates with the existing ephrinA repellent gradient to regulate topographic specific branching along the A-P tectal axis. Theoretically, this activity could be a branch repellent gradient counter to the ephrinA gradient, as modeled here, or a branch promoting gradient parallel to the ephrinA gradient, with corresponding gradients of receptors in the retina. The hypothetical counter-repellent to the existing ephrinA repellent gradient used in our model is mediated by ephrinAs and EphAs expressed by RGCs and OT/SC cells, respectively. However, other repellent activities that meet the appropriate criteria could be substituted for them.

Considerable data show that the related family members, EphB "receptors" and the transmembrane ephrinB "ligands", bidirectionally signal, and that reverse signaling into ephrinB expressing cells has important roles in numerous phenomena, including axon guidance and mapping (Henkemeyer et al., 1996; Holland et al., 1996; Bruckner et al., 1997). In the developing retinotectal projection, both EphB forward signaling and ephrinB reverse signaling have roles in mapping the dorsoventral retinal axis along the mediolateral axis of the OT/SC (Hindges et al., 2002; Mann et al., 2002; McLaughlin et al., 2003b). Although ephrinAs are linked to the axonal membrane by a GPI anchor, accumulating evidence indicates that ephrinAs can act as receptors for EphAs, and through association with other proteins signal into the axon (Knoll and Drescher, 2002). In vivo and in vitro experimental findings suggest that ephrinAs on vomeronasal and olfactory axons do act as receptors (Knoll et al., 2001; Cutforth et al., 2003). Biochemical studies in cell lines have also provided evidence that ephrinAs can act as receptors for EphAs and, presumably by complexing with other proteins, signal into ephrinA- expressing cells (Huai and Drescher, 2001). Thus, the countergradients of expression of EphAs and ephrinAs in both RGCs and the OT/SC may well function bidirectionally in mediating retinotectal map development.

In addition to the EphA/ephrinA countergradients, other activities likely have a role in map development. For example, RGC axons must have an intrinsic ability to branch along their length and/or external signals such as BDNF promoting branching and arborization (Cohen-Cory and Fraser, 1995; Choi and O'Leary, 1999; Cohen-Cory, 1999). Several lines of evidence suggest the presence of other activities also involved in A-P mapping. For example, although the retinocollicular map is very aberrant in the ephrinA2/A5 double knockout mouse, it does exhibit some organization along the A-P axis in the absence of any ephrinAs in the SC (Feldheim et al., 2000). In addition, ectopic retinal expression of the transcription factors, BF1, BF2 (Yuasa et al., 1996), SOHo1 or GH6 (Schulte and Cepko, 2000), that are normally differentially expressed along the T-N axis result in aberrant A-P topographic mapping by a mechanism that appears to be distinct from a regulation of EphAs and ephrinAs. Among the molecules that may account for these findings is the recently cloned RGM (Monnier et al., 2002), which was initially identified biochemically by Bonhoeffer and colleagues (Stahl et al., 1990). RGM 
is expressed in a low to high A-P gradient in the chick OT and is a repellent that preferentially affects temporal RGC axons (Muller et al., 1996). An unidentified activity associated with posterior chick OT has been reported to promote in vitro the preferential growth of nasal RGC axons (von Boxberg et al., 1993). Neural activity also has a role in map refinement because a proportion of overshooting RGC axons and ectopic arbors survive the normal refinement period in chicks and rats when retinal activity is blocked (Kobayashi et al., 1990; Simon et al., 1992).

Maximizing the relevance of a model to a developing biological system requires that the model incorporates known parameters and recapitulates the developmental process being modeled. The dynamics of map development and refinement in our simulations parallel those described in vivo in chick OT and rodent SC (Nakamura and O'Leary, 1989; Simon and O'Leary, 1992a,b; Yates et al., 2001). Initially in our chick simulation, large increases are seen in both the number of primary branches (those originating directly from the axon shaft) and higher order branches generated. The rate of increase quickly levels off as total repellent levels increase and dramatically limit new branch formation, followed by a longer second phase where total branching increases more slowly, and higher order branch formation is partially balanced by branch loss. A third phase then begins where total branching reaches a steady state, though an increase in topographic specificity of branch distribution continues. This steady state increase in branch specificity is due to the generation and maintenance of new branches within the correct $\mathrm{TZ}$ counterbalanced by a net removal of branches outside the TZ. The same specificity and dynamics in branching are observed during chick retinotectal map development in vivo (Yates et al., 2001). The same parameters that generate topographic branching and arborization in our simulations also result in elimination of the posterior segments of overshooting axons back to the point of a sustaining branch and arbor, and a proportion of axons are actually lost entirely. Both of these features also occur during normal in vivo map development (Nakamura and O'Leary, 1989; Yates et al., 2001). It is particularly interesting that axon elimination occurs in the simulations because this feature is not specifically programmed into the model, but is a by-product of an axon's success, or lack thereof, in the process of interstitial branching and arborization. This relationship between the viability of an entire RGC axon or its distal overshooting portion and the formation of a sustaining arbor has been suggested to explain in vivo observations (O'Leary et al., 1986;
Nakamura and O'Leary, 1989), and is supported by findings from the simulations.

In addition to normal map development, the model replicates the reported phenotypes in mutant mice with altered EphA and ephrinA levels. The simulations demonstrate that simply lowering ephrinA levels, with no other parameter changes, can account for most of the observed ephrinA knockout phenotypes (Frisen et al., 1998; Feldheim et al., 2000). In the simulations of ephrinA deficient mice, map development is driven even more by the added repellents than in wild-type, with the remaining lower level of SC repellent providing only a very slight topographic bias to initial branching. The added repellents amplify this initial modest topographic bias in branching to produce a substantially greater degree of topographic order. However, the weaker bias in branching allows for focal concentrations of ectopic branches to form by chance. If an ectopic cluster of branches becomes dense enough it inhibits topographically appropriate branching and is maintained as an ectopic TZ. The modeling also suggests that the phenotype described for nasal axons in ephrinA knockouts (Feldheim et al., 2000) may be due in large part to a decrease in retinal counter-receptor ephrinA signaling, contributing to a secondary increase in the level of functional EphA receptors in nasal RGCs due to a reduced ephrinAmediated receptor inactivation.

Previous descriptions of ephrinA deficient mice suggested that lower SC ephrinA levels allow temporal axons to form ectopic arbors posteriorly (Frisen et al., 1998). Our model suggests that the lower ephrinA levels on nasal RGC axon arbors is also a critical factor that allows temporal RGC axons to form ectopic arbors posteriorly in ephrinA knockout mice. Similarly, the model suggests that the lower ephrinA on nasal RGC axonal arbors results in less repulsion by temporal RGC axon arbors, and is a critical factor in allowing nasal RGC axons to arborize ectopically in anterior positions. This adds to a previous interpretation of this phenotype, which proposed that diminished ephrinA levels in nasal RGCs increases their functional pool of EphA receptors, resulting in increased repulsion by ephrinA expressed in posterior SC (Feldheim et al., 2000).

The simulations of the Is12-EphA3 knockin mice closely replicate the in vivo phenotypes of both homozygous and heterozygous knockins and suggest interesting roles and distinctions for mechanisms based on neighbor-neighbor RGC relationships and the molecular control of RGC mapping. Results from these model simulations strongly suggest that axonaxon interactions controlled by their expression of axon repellents, rather than activity-dependent mech- 
anisms, are responsible for both the compression and shift in the maps formed by the knockin and wild-type RGCs. The degree of posterior shift in the map of wild-type RGCs is affected by SC-expressed repellent and less shift should occur as the ratio of SC repellent to added RGC arbor repellent increases. In the wildtype simulations, we conclude that the branchdensity and added repellent parameters cooperate significantly to refine the topographic map. The knockin simulations provide a compelling demonstration of this cooperation. With the branchdensity parameter alone, some map refinement occurs, but significantly less than when combined with the added repellents parameter. More importantly, if the added repellents parameter is removed, the TZs for the wild-type RGCs do not shift posteriorly as observed in vivo, but instead they form at their topographically appropriate locations within the SC. Thus, the added repellents parameter initiates the posterior shift, and the branchdensity term reinforces it, resulting in a final map with wild-type TZs posterior to their topographically appropriate locations.

In conclusion, this model demonstrates that EphAs and ephrinAs acting as counter-repellents are sufficient to recapitulate the principle features of topographic map development, yet they allow for additional activities that might act in redundant or reinforcing manners, resulting in a precise topographic map. The model suggests novel roles for EphAs and ephrinAs in retinocollicular map development in vivo and provides a framework for further investigations. The roles of EphAs and ephrinAs in map development are likely to be multiple and complex. A complete and accurate accounting of these roles will require careful dissection of potential EphA/ ephrinA interactions through the use of tissue specific knockout and knockin technologies, and various mutant combinations.

Note added in proof: The simulations of mouse retinocollicular mapping presented in this paper predicted that the proper refinement of the map requires a process similar to that assumed for spontaneous correlated retinal activity. We investigated this prediction in vivo after the simulations were completed. We find that mutant mice that retain spontaneous RGC activity, but lack retinal waves and the neighbor correlations generated by them, fail to form dense, focal TZs and instead have broad, diffuse TZs, as predicted by the simulations. The outcome of simulations performed with the branchdensity parameter is strikingly similar to the appearance of TZs formed in wild-type mice at P8 (compare [Fig. 4(B)] in this paper to [Fig. 6(A)] in McLaughlin et al., 2003, Neuron). In addition, the outcome of simulations performed without the branchdensity parameter is strikingly similar to the appearance of the diffuse TZs formed at P8 in mutant mice that lack retinal waves (compare [Fig. 4(A)] in this paper to [Fig. 6(B,C)] in McLaughlin et al., 2003, Neuron).

T.M. received fellowship support from the Neuroplasticity of Aging Training Grant (T32 AG00216). We thank Charles Stevens for helpful discussions. We gratefully acknowledge the inspirational contributions of Friederich Bonhoeffer and thank him for invigorating the field of neural specificity and providing the framework for molecular analyses of axon guidance.

\section{REFERENCES}

Baier H, Bonhoeffer F. 1992. Axon Guidance by Gradients of a Target-Derived Component. Science 255:472-475.

Bonhoeffer F, Gierer A. 1984. How do retinal axons find their targets in the tectum? Trends Neurosci 7:73787381.

Bonhoeffer F, Huf J. 1982. In vitro experiments on axon guidance demonstrating an anterior-posterior gradient on the tectum. EMBO J 1:427-431.

Bonhoeffer F, Huf J. 1985. Position-dependent properties of retinal axons and their growth cones. Nature 315:409410.

Brown A, Yates PA, Burrola P, Ortuno D, Vaidya A, Jessell TM, Pfaff SL, O'Leary DDM, Lemke G. 2000. Topographic mapping from the retina to the midbrain is controlled by relative but not absolute levels of EphA receptor signaling. Cell 102:77-88.

Bruckner K, Pasquale EB, Klein R. 1997. Tyrosine phosphorylation of transmembrane ligands for Eph receptors. Science 275:1640-1643.

Cheng HJ, Flanagan JG. 1994. Identification and cloning of ELF-1, a developmentally expressed ligand for the Mek4 and Sek receptor tyrosine kinases. Cell 79:157-168.

Cheng HJ, Nakamoto M, Bergemann AD, Flanagan JG. 1995. Complementary gradients in expression and binding of ELF-1 and Mek4 in development of the topographic retinotectal projection map. Cell 82:371381.

Choi O, O'Leary DDM. 1999. Potential role of BDNF and TrkB in developing topographic retinotectal projections. Soc Neurosci Abstr 25:242.

Cohen-Cory S. 1999. BDNF modulates, but does not mediate, activity-dependent branching and remodeling of optic axon arbors in vivo. J Neurosci 19:9996-10003.

Cohen-Cory S, Fraser SE. 1995. Effects of brain-derived neurotrophic factor on optic axon branching and remodelling in vivo. Nature 378:192-196.

Connor RJ, Menzel P, Pasquale EB. 1998. Expression and tyrosine phosphorylation of Eph receptors suggest multiple mechanisms in patterning of the visual system. Dev Biol 193:21-35.

Cutforth T, Moring L, Mendelsohn M, Nemes A, Shah NM, Kim MM, Frisen J, Axel R. 2003. Axonal ephrin-As and 
odorant receptors. Coordinate determination of the olfactory sensory map. Cell 114:311-322.

Davis S, Gale NW, Aldrich TH, Maisonpierre PC, Lhotak V, Pawson T, Goldfarb M, Yancopoulos GD. 1994. Ligands for EPH-related receptor tyrosine kinases that require membrane attachment or clustering for activity. Science 266:816-819.

Debski EA, Cline HT. 2002. Activity-dependent mapping in the retinotectal projection. Curr Opin Neurobiol 12:9399.

Drescher U, Kremoser C, Handwerker C, Loschinger J, Noda M, Bonhoeffer F. 1995. In vitro guidance of retinal ganglion cell axons by RAGS, a $25 \mathrm{kDa}$ tectal protein related to ligands for Eph receptor tyrosine kinases. Cell 82:359-370.

Feldheim DA, Kim YI, Bergemann AD, Frisen J, Barbacid M, Flanagan JG. 2000. Genetic analysis of ephrin-A2 and ephrin-A5 shows their requirement in multiple aspects of retinocollicular mapping. Neuron 25:563-574.

Feldheim DA, Vanderhaeghen P, Hansen MJ, Frisen J, Lu Q, Barbacid M, Flanagan JG. 1998. Topographic guidance labels in a sensory projection to the forebrain. Neuron 21:1303-1313.

Flanagan JG, Vanderhaeghen P. 1998. The ephrins and Eph receptors in neural development. Annu Rev Neurosci 21:309-345.

Fraser SE, Hunt RK. 1980. Retinotectal specificity: models and experiments in search of a mapping function. Annu Rev Neurosci 3:319-352.

Frisen J, Yates PA, McLaughlin T, Friedman GC, O'Leary DDM, Barbacid M. 1998. Ephrin-A5 (AL-1/RAGS) is essential for proper retinal axon guidance and topographic mapping in the mammalian visual system. Neuron 20:235-243.

Gale NW, Holland SJ, Valenzuela DM, Flenniken A, Pan L, Henkemeyer M, Strebhardt K, Hirai H, Wilkinson DG, Pawson T, et al. 1996. Eph receptors and ligands comprise two major specificity subclasses, and are reciprocally compartmentalized during embryogenesis. Neuron 17:9-19.

Gierer A. 1983. Model for the retino-tectal projection. Proc R Soc Lond B Biol Sci 218:77-93.

Gierer A. 1987. Directional cues for growing axons forming the retinotectal projection. Development 101:479-489.

Goodhill GJ, Richards LJ. 1999. Retinotectal maps: molecules, models and misplaced data. Trends Neurosci 22: 529-534.

Harris WA. 1980. The effects of eliminating impulse activity on the development of the retinotectal projection in salamanders. J Comp Neurol 194:303-317.

Harris WA. 1984. Axonal pathfinding in the absence of normal pathways and impulse activity. J Neurosci 4:1153-1162.

Henkemeyer M, Orioli D, Henderson JT, Saxton TM, Roder J, Pawson T, Klein R. 1996. Nuk controls pathfinding of commissural axons in the mammalian central nervous system. Cell 86:35-46.
Hindges R, McLaughlin T, Genoud N, Henkemeyer M, O'Leary DDM. 2002. EphB forward signaling controls directional branch extension and arborization required for dorsal-ventral retinotopic mapping. Neuron 35:475-487.

Holland SJ, Gale NW, Mbamalu G, Yancopoulos GD, Henkemeyer M, Pawson T. 1996. Bidirectional signaling through the EPH-family receptor Nuk and its transmembrane ligands. Nature 383:722-725.

Honda H. 1998. Topographic mapping in the retinotectal projection by means of complementary ligand and receptor gradients: a computer simulation study. J Theor Biol 192:235-246.

Hornberger MR, Dutting D, Ciossek T, Yamada T, Handwerker C, Lang S, Weth F, Huf J, Wessel R, Logan C, et al. 1999. Modulation of EphA receptor function by coexpressed ephrinA ligands on retinal ganglion cell axons. Neuron 22:731-742.

Huai J, Drescher U. 2001. An ephrin-A-dependent signaling pathway controls integrin function and is linked to the tyrosine phosphorylation of a $120-\mathrm{kDa}$ protein. J Biol Chem 276:6689-6694.

Knoll B, Drescher U. 2002. Ephrin-As as receptors in topographic projections. Trends Neurosci 25:145-149.

Knoll B, Zarbalis K, Wurst W, Drescher U. 2001. A role for the EphA family in the topographic targeting of vomeronasal axons. Development 128:895-906.

Kobayashi T, Nakamura H, Yasuda M. 1990. Disturbance of refinement of retinal projection in chick embryos by tetrodotoxin and grayanotoxin. Dev Brain Res 57:29-35.

Mann F, Ray S, Harris W, Holt C. 2002. Topographic mapping in dorsoventral axis of the Xenopus retinotectal system depends on signaling through ephrin-B ligands. Neuron 35:461-473.

Marcus RC, Gale NW, Morrison ME, Mason CA, Yancopoulos GD. 1996. Eph family receptors and their ligands distribute in opposing gradients in the developing mouse retina. Dev Biol 180:786-789.

McLaughlin T, Hindges R, O’Leary DDM. 2003a. Regulation of axial patterning of the retina and its topographic mapping in the brain. Curr Opin Neurobiol 13:57-69.

McLaughlin T, Hindges R, Yates PA, O'Leary DDM. 2003b. Bifunctional action of ephrin-B1 as a repellent and attractant to control bidirectional branch extension in dorsal-ventral retinotopic mapping. Development 130: 2407-2418.

McLaughlin T, O’Leary DDM. 1999. Functional consequences of coincident expression of EphA receptors and ephrin-A ligands. Neuron 22:636-639.

McLaughlin T, Torborg CL, Feller MB, O'Leary DDM. 2003. Retinotopic map refinement requires spontaneous retinal waves during a brief critical period of development. Neuron 40:1147-1160.

Monnier PP, Sierra A, Macchi P, Deitinghoff L, Andersen JS, Mann M, Flad M, Hornberger MR, Stahl B, Bonhoeffer $\mathrm{F}$, et al. 2002. RGM is a repulsive guidance molecule for retinal axons. Nature 419:392-395.

Monschau B, Kremoser C, Ohta K, Tanaka H, Kaneko T, Yamada T, Handwerker C, Hornberger MR, Loschinger 
J, Pasquale EB, et al. 1997. Shared and distinct functions of RAGS and ELF-1 in guiding retinal axons. EMBO J 16:1258-1267.

Montague PR, Gally JA, Edelman GM. 1991. Spatial signaling in the development and function of neural connections. Cereb Cortex 1:199-220.

Muller BK, Jay DG, Bonhoeffer F. 1996. Chromophoreassisted laser inactivation of a repulsive axonal guidance molecule. Curr Biol 6:1497-1502.

Nakamoto M, Cheng HJ, Friedman GC, McLaughlin T, Hansen MJ, Yoon CH, O'Leary DDM, Flanagan JG. 1996. Topographically specific effects of ELF-1 on retinal axon guidance in vitro and retinal axon mapping in vivo. Cell 86:755-766.

Nakamura H, O'Leary DDM. 1989. Inaccuracies in initial growth and arborization of chick retinotectal axons followed by course corrections and axon remodeling to develop topographic order. J Neurosci 9:3776-3795.

O'Leary DDM, Fawcett JW, Cowan WM. 1986. Topographic targeting errors in the retinocollicular projection and their elimination by selective ganglion cell death. J Neurosci 6:3692-3705.

O'Leary DDM, Yates PA, McLaughlin T. 1999. Molecular development of sensory maps: representing sights and smells in the brain. Cell 96:255-269.

O'Rourke NA, Cline HT, Fraser SE. 1994. Rapid remodeling of retinal arbors in the tectum with and without blockade of synaptic transmission. Neuron 12:921-934.

Rosentreter SM, Davenport RW, Loschinger J, Huf J, Jung J, Bonhoeffer F. 1998. Response of retinal ganglion cell axons to striped linear gradients of repellent guidance molecules. J Neurobiol 37:541-562.

Schulte D, Cepko CL. 2000. Two homeobox genes define the domain of EphA3 expression in the developing chick retina. Development 127:5033-5045.

Shatz CJ. 1990. Competitive interactions between retinal ganglion cells during prenatal development. J Neurobiol 21:197-211.

Simon DK, O'Leary DDM. 1992a. Responses of retinal axons in vivo and in vitro to molecules encoding position in the embryonic superior colliculus. Neuron 9:977-989.

Simon DK, O'Leary DDM. 1992b. Development of topographic order in the mammalian retinocollicular projection. J Neurosci 12:1212-1232.
Simon DK, Prusky GT, O’Leary DDM, Constantine-Paton M. 1992. N-methyl-D-aspartate receptor antagonists disrupt the formation of a mammalian neural map. Proc Natl Acad Sci USA 89:10593-10597.

Sperry R. 1963. Chemoaffinity in the orderly growth of nerve fiber patterns and connections. Proc Natl Acad Sci USA 50:703-710.

Stahl B, Muller B, von Boxberg Y, Cox EC, Bonhoeffer F. 1990. Biochemical characterization of a putative axonal guidance molecule of the chick visual system. Neuron 5:735-743.

Stuermer CA, Rohrer B, Munz H. 1990. Development of the retinotectal projection in zebrafish embryos under TTXinduced neural-impulse blockade. J Neurosci 10:36153626.

Thanos S, Bonhoeffer F, Rutishauser U. 1984. Fiber-fiber interaction and tectal cues influence the development of the chicken retinotectal projection. Proc Natl Acad Sci USA 81:1906-1910.

von Boxberg Y, Deiss S, Schwarz U. 1993. Guidance and topographic stabilization of nasal chick retinal axons on target-derived components in vitro. Neuron 10:345357.

Walter J, Henke-Fahle S, Bonhoeffer F. 1987a. Avoidance of posterior tectal membranes by temporal retinal axons. Development 101:909-913.

Walter J, Kern-Veits B, Huf J, Stolze B, Bonhoeffer F. 1987b. Recognition of position-specific properties of tectal cell membranes by retinal axons in vitro. Development 101:685-696.

Willshaw DJ, von der Malsburg C. 1976. How patterned neural connections can be set up by self-organization. Proc R Soc Lond B Biol Sci 194:431-445.

Wong ROL. 1999. Retinal waves and visual system development. Annu Rev Neurosci 22:29-47.

Yates PA, Roskies AL, McLaughlin T, O'Leary DDM. 2001. Topographic-specific axon branching controlled by ephrin-As is the critical event in retinotectal map development. J Neurosci 21:8548-8563.

Yuasa J, Hirano S, Yamagata M, Noda M. 1996. Visual projection map specified by topographic expression of transcription factors in the retina. Nature 382:632635. 